\title{
Sobre la filosofía moral de Ortega y las dificultades de su recepción
}

\author{
MAX STERN
}

Es habitual que toda evaluación sumaria de la obra filosófica de Ortega provoque de forma más o menos inmediata una discusión sobre la existencia o no de una tradición filosófica española (o de una tradición filosófica en lengua castellana) y, en caso de que la discusión no se zanje demasiado negativamente, se suela proseguir con disputas de muy variado tono a propósito de la índole de esa tradición, su importancia, sus límites y cosas por el estilo. Esto no debería resultar extraño. Ortega pertenece sin duda al canon filosófico - al conjunto de autores cuyo examen se tiene por filosóficamente significativo-. pero pertenece a él de modo harto peculiar. Normalmente, a los filósofos se los lee y se los comenta con la confianza de que lo que dicen es pertinente para el planteamiento de problemas que sc juzgan interesantes. Otras veces, algunos filósofos ofrecen material abundante para edificar la visión del mundo que uno quiere formarse, o proporcionan cierto vocabulario o cierto estilo de hablar que se piensa puede ser fructífero con vistas a los propósitos más variados. Para ganarse un sitio en el canon, las obras de un filósofo necesitan haber acreditado que son aptas para alguno de esos usos y, normalmente, para más de uno. $i^{\text {Es por alguna de estas razones }}$ por las que se juzga que Ortega es un filósofo digno de tomarse en serio? Aunque resulta muy difícil responder negativamente a esta pregunta, las respuestas positivas que se le suelen dar resultan a veces algo inquietantes, y aun cabe maliciarse que, en ocasiones, constituyen el precio que hay que pagar por sostener a toda costa la vigencia - - la la deseabilidad - de una tradición nacional en filosofía.

¿Por qué al hablar de Ortega se suscita una discusión sobre la tradición filosófica española? Este problema puede deslindarse en dos. El primero se podría formular con esta pregunta: cexisten genuinas tradiciones nacionales en filosofía y, supuesto que existan, constituyen entidades dignas de una atención no anecdótica? Se trata de una interesante cuestión metafilosófica que anda relacionada además con problemas estrictamente filosóficos bastante palpitantes. En filosofía moral y en filosofía de la ciencia, por ejemplo, el problema de las tradiciones dista mucho de ser una cuestión trivial. Si es lícito hacerse esa pregunta en su formulación general, también lo será plantearla en lo relativo a España (o reformularla de modo que alli donde se habla de tradiciones nacionales se hable de tradiciones en determinada lengua). Pero, a propósito de Ortega, esta pregunta suele conducir a otra distinta, que podría enunciarse así: imerece la pena reconstriir una tradición filosófica nacional en España (o una tradición filosófica en lengua castellana)? Que la primera pregunta lleve a la segunda es un indicio de que, cuando la retórica se deja a un lado, casi nadie está convencido de la existencia, en España o en castellano, de una genuina tradición filosófica, cualquier cosa que sea lo que esto signifique. Para muchas gentes y por motivos muy variados, lo anterior es una verdad incómoda y desagradable. Ellos juzgan que la existencia de una sólida tradición de pensa- 
miento es un factor positivo (incluso imprescindibley para el desarrollo de las ideas y deciden que, puesto que es bueno que las ideas se desarrollen al máximo, ha de haber una tradición que avale y sustente dicho desarrollo. Esta argumentación es burdamente lalaz, como sabe todo alumno de primer curso, pero reconocer que es falaz resulta incómodo $\mathrm{y}$, muchas veces, frustrante. No todos los que incurren en la falacia de la tradición son, ni mucho menos, nacionalistas groseros y pedestres; abunda, por el contrario, el entrañable tipo humano del regeneracionista, la encarnación más enternecedora del wishful thinking jamás soñada. ¿Qué hacer, pues? Hay que reconstruir, piensa el amante de las tradiciones nacionales, la genuina tradición de pensamiento a que pertenecemos. Pero «reconstruir" puede aquí querer decir cosas muy distintas. No parece que denote nada por el estilo de volver a edíficar lo que quedó destruido. El corpus filosófico español está razonablemente bien editado y disponible, y no precisa de una labor filológica hercúlea enderezada a sacarlo a la luz. Descubrir nuevas obras de krausistas olvidados o rescatar a librepensadores de segunda fila es una empresa de cuyo interés historiografico y sociologico nadie duda, pero sería insensato imaginar que tenga algo que ver con problema filosófico alguno. "Reconstruir» parece referirse a algo distinto. Parece sugerir que hay una genuina tradición que desconocemos y que, debidamente conocida, habría de proporcionar el suelo nutricio del que se dice carecer.

El principal problema de esa tradición es, empero, que no existe. Cuando se proporciona un relato coherente de esa pretendida entidad, el resultado es decepcionante, y obliga a modificar ad hoc las expectativas que se habian formado. Se quería anibar a tierra firme y lo que se halla es un modesto archipié- lago de islotes pantanosos. Respuesta: la tradición hispana es pantanosa e insular, cosa que no ha parecer extraña -piensa el tradicionalista- porque las tradiciones se caracterizan por ser cada una de muy distinto linaje. El genuinamente español tendría como divisa la pantanosidad, una divisa desde luego tan respetable como cualquier otra.

Hasta 1936, fue Ortega el principal animador de una fecunda comunidad de escritores, artistas, cientificos y eruditos que unían a la excelencia de su oficio una seria sensibilidad civil. Además, en tomo a Ortega pudo formarse en la Universidad de Madrid una buena sección de filosofía allí donde treinta años antes se erguía una tribuna ocasional de personajes pintorescos y de clero ultramontano. El filósofo madrileño constituyo el centro de un polígono de fuerzas en cuyos vértices se hallaban instituciones señeras: la Residencia de Estudiantes, el Ateneo, la Revista de Occidente, el Instituto-Escuela, el Centro de Estudios Históricos $\mathrm{y}$, en los años treinta, la Facultad de Filosofía y Letras configuraron un espacio mental y civil irrepetible. Ortega fue la figura más brillante de aquella espléndida constelación a la que se ha llamado la wedad de plata de la cultura española y el más destacado artífice de una notable renovación del ambiente filosófico gracias a la cual pudo producirse una original recepción del pensamiento alemán de la época $y$, por vez primera, un estudio riguroso de los clásicos de la filosofía moderna.

Los efectos de la victoria franquista, devastadores en su conjunto, fueron distintos a largo plazo en esos dos ámbitos de la actuación de Ortega, el genéricamente cultural y el específicamente filosófico. Es cierto que la edad de plata terminó en 1936 (o quizá en 1939) y que la cultura oficial que vino a sustituirla constituyó un acabado espécimen de 
barbarie. También es verdad que, cuantitativa y cualitativamente, el fenómeno del exilio intelectual fue lo bastante fuerte para impedir toda continuidad, siquiera subterránea, del ambiente literario, artístico y científico anterior a la guerra. Pero no conviene olvidar que aquella comunidad intelectual, traumáticamente rota, pervivió en el interior del país bajo la forma de núcleos más o menos aislados de resistencia cultural. Sólo así puede explicarse, como ha señalado Aranguren, que el verdadero establishment cultural del país a la altura de los últimos sesenta no era ya el aparato intelectual franquista sino la reconstruida cultura liberal ( $L a$ cultura española y la cultura establecida, Madrid, Taurus, 1975, pp. 13-15, 160-164). Esto, que tiene una coloración predominantemente madrileña, es todavía más llamativo en el caso de la cultura catalana. Bien poco de la historia intelectual española de las dos últimas décadas se explicaría sin ese fenómeno.

Nada parecido puede afirmarse en lo referente a la pequeffa pero importante comunidad filosófica surgida en torno a Ortega antes de la guerra. En la época en que la tradición liberal se había adueñado ya de la alta cultura madrileña y española, un joven nacido en los años cuarenta podía a veces aspirar a una carrera artística o literaria típica de cualquier país normal, o podía formarse como historiador, como economista o como filólogo de un modo digno (y muchas veces más que digno). Pero ciertamente nada parecido ocumía en el campo de la fllosofía. Mientras otros cultivadores de las humanidades tendían puentes sin demasiada dificultad con el pasado anterior a la guerra civil, a los filósofos españoles de los años sesenta y setenta no les fue dado el continuar la tradición de Ortega, de Gaos, de García Morente o de Zubiri. Tan sólo figuras muy aisladas podian desempeñar esa función. Cuando se abrió alguna brecha importante, como el paso de José Luis L. Aranguren por la Universidad de Madrid, esc magisterio sìrvió más para despertar nuevas tendencias filosóficas de procedencia continental o anglosajona que para enhebrar un hilo de continuidad con el pensamiento anterior a la guerra. La generación filosófica que enterró definitivamente la neoescolastica franquista no pudo enlazar con aquella tradición - con Ortega mismo, para lo que aquí nos interesa- y probablemente tampoco quiso. Entre sus más destacados representantes, el papel de Ortega puede que fuera notable como experiencia formativa, pero el hecho es que influyó poco en la cristalización de sus horizontes teóricos, y esto no ha de atribuirse a los efectos de la represión franquista ni a nada semejante. No sé cuánto valor de síntoma ha de conccderse al conocido sepisodio de la manzana» de Tiempo de silencio, pero lo cierto es que las obras de Ortega se hallaban ampliamente disponibles, y que, salvo para sus discípulos y comentaristas más fieles, su lector tipo era más bien el lector culto en busca de ensayo culto que el lector filosófico. Ni la filosofía analítica, ni las distintas corrientes deudoras del marxismo occidental ni las tendencias nietzscheanas $y$ estructuralistas que tanto proliferaron entonces debieron gran cosa a Ortega, quien constituía más bien un vago referente cultural que un clásico al que tomar en serio. Ni siquiera está claro que en la recepción de la hermenéutica o en la del segundo Heidegger contase demasiado el precedente de Ortega, tan protagonista, en cambio, en la pronta incorporación de la fenomenología y de la analítica existencial antes de la guenra. La problemática y precaria tradición filosófica de la Escuela de Madrid fue una tradición interrumpida, en parte por la ruptura material de la misma $y$ en parte porque na- 
die (salvo los comentaristas de Ortega) tuvo demasiado interés en continuarla. ¿Por qué, pues, empeñarse en contextualizar la obra de Ortega en una tradición de pensamiento que dudosamente existe?

Si llevo razón en lo que he esbozado sobre el problema de las tradiciones filosóficas nacionales, sobre la ausencia de una genuina tradición filosófica en castellano y sobre la ruptura de la precaria tradición filosófica de la Escuela de Madrid, ha de concedérseme que toda lectura filosóficamente fecunda de la obra de Ortega necesita una severa cura de desintoxicación. Esto parece implicar que la recepción habitual del pensador madrileño se halla cruzada por referencias que bloquean una lectura filosóficamente interesante, y en verdad lo implica, a condición, claro está, de no llevar los cuidados antisépticos hasta el extremo de confundir la recepción con lo recibido. Podemos seguir leyendo a Ortega como a un brillante polígrafo que nos ilustra sobre gran número de curiosidades; podemos seguirle teniendo como modelo de prosa castellana; podemos admirar su sensibilidad literaria aun deplorando acaso algunos rasgos de su recórica política; podemos, desde luego, aunque no constituya un ejercicio demasiado atractivo, proseguir hasta la extenuación su exégesis y ensayar sistematizaciones coherentes de su pensamiento, y no nos está prohibido, por cierto, meditar hasta el hartazgo sobre la esencia y el destino de la identidad española y su circunstancia. Pero nada de esto parece muy fecundo. $\measuredangle \mathrm{Ha}$ de concluirse que Ortega es, si acaso, un autor interesante para el historiador de las ideas y para el sociologo de la cultura?

Propondré una hipótesis contrafáctica que creo tiene asegurado un cuantioso aluvión de rechazos. Imaginemos que Ortega es un filósofo extranjero (ale- mán, sin ir más lejos) que vivió entre 1883 y 1955 , se interesó episódicamente por asuntos de la literatura y la política españolas, es objeto frecuente de estudio en los departamentos de filosofía (no en los de filología románica) europeos y americanos más representativos de las últimas tendencias de la filosofía contemporánea $\mathrm{y}$, por azar, su obra se halla en su totalidad vertida al castellano por un único traductor, individuo de peculiar estilo literario. No es necesario que se me replique que un Ortega así transfigurado no sería Ortega: podriámos bautizarlo como mejor conviniese. También es cierto que con la transfiguración se perderian elementos contextuales imprescindibles para entender cabalmente a Ortega; sin embargo, no parece que la lectura de un clásico de la filosofía sea nada distinto de la invención de un contexto en el que ese clásico resulte interesante. Un amigo poco simpatético con la filosofía de Ortega me replicó al conocer esta hipótesis contrafáctica que, si se adoptara, entonces la lectura de Ortega sería perfectamente inútil. Ortega, según mi amigo, se reduciría a su contexto; al leerle, emprenderíarnos en último término un trabajo de documentación; Ortega sería un mero vicario de su circunstancia. Aquella conversación me recordó un provocativo comentario de Jon Elster a propósito de Leibniz. Al comienzo de su libro Leibniz et la formation de l'esprit capitaliste, afimaba Elster por los años de mayor boga historicista en filosofía de la ciencia que algunos autores, aun no careciendo de contexto, pueden y deben leerse y entenderse como si carecieran de él. Con ello, el filosofo noruego no queria establecer un principio hermenéutico general ni nada por el estilo. Simplemente deseaba constatar lo que a su juicio ocurría con Leibniz, por más que su propio libro pueda entenderse como una feliz refutación de tan drásti- 
ca tesis. Estoy muy lejos de compartir el entusiasmo whiggish de Elster, pero también del pesimismo hiperhistoricista de mi amigo. Quizá sea un buen experimento mental someter a los clásicos a lo que podriamos llamar el "test de la descontextualización», aunque no convendría confiar en él tanto como para expulsar $\sin$ más del canon cultural a quienes no superasen la prueba. Al fin y al cabo, la historia intelectual se hace a base de descontextualizaciones de gran envergadura, nunca desde luego tan explícitas y premeditadas como en mi experimento mental.

¿Aprobaría Ortega el test de la descontextualización en la forma que le he dado? $Y$, en caso de que lo aprobase, ¿se ganaría algo desde el punto de vista hermenéutico? ¿podrian suscitarse problemas filosóficos interesantes que de otro modo nunca se habrían planteado? En lo que sigue, no voy a intentar responder a estas preguntas. Tan sólo voy a esbozar algunos argumentos sobre la filosofía moral de Ortega apoyándome en la hipótesis de Ortega como filosofo extranjero, aunque acaso seré inconsecuente con mi propia hipótesis en más de un punto.

¿Hay en Ortega una filosofía moral? Salvo que se esté dispuesto a dar una definición estipulativa del têrmino con los ojos puestos en una respuesta afirmativa, resulta claro que Ortega no es el autor de una reflexión articulada y sistemática sobre el fenómeno de la moralidad. Pero esta respuesta negativa es tambien insatisfactoria. ¿No es verdad que la obra de Ortega está llena de sugerencias de una ethica utens a menudo vigorosa y que hay en el una suerte de preocupación moral genérica que se percibe en los rincones más insospechados de su pensamiento?

Probablemente, es estéril definir con rigor el estatuto de las reflexiones de Ortega sobre moral. En Ortega hay algo menos que una ética y algo mảs que una mera suma de intuiciones morales propias de un robusto esprit de finesse, y basta con admitir que muchas de sus reflexiones sobre moralidad resultan fecundas y penetrantes para dar por sentado que la ética contemporánea podría extraer no poco provecho de las mismas. Pedro Cerezo ha mostrado con exactitud la manera como las preocupaciones éticas de Ortega cristalizan en la propuesta de una "moral del héroe" que recorre, desde las Meditaciones del Quijote, toda su obra filosófica ( $L a$ voluntad de aventura, Barcelona, Ariel, 1984, pp. 339-375). Las inquietudes del Ortega de las Meditaciones poseerían una triple raíz. De un lado, Ortega necesita un ajuste de cuentas con el neokantismo en materia de ética; el idealismo ético es, para el Ortega de 1914, un manco insuficiente para la reflexión sobre la moralidad y acaso también un marco perturbador; una ética del deber es una ética desenfocada que no da cuenta de las intuiciones morales básicas del autor de las Meditaciones. Antes de que en 1921, en España inveriebrada, hablara de una "magia del "debe ser" " distorsionadora de la recta percepción del devenir natural de las cosas, Ortega había expulsado todo formalismo ético del universo de sus preocupaciones. Si Ortega fuese el autor de una filosofía moral, no cabe ninguna duda de que la suya habria sido una ética antikantiana, desentendida por completo de todo ideal de fundamentación y hostil a todo universalismo moral.

Una segunda fuente de preocupaciones vino dada por la enemiga de Ortega a la tradición utilitarista en filosofía práctica. Para êl, el utilitarismo es la otra cara de la moneda idealista. Pues, de la misma forma en que las éticas deontológicas absuelven a la subjetividad de toda necesidad de autocreación $y$ de descubrimiento de su verdadero 
yo, las êticas teleológicas del bienestar yerran totalmente en su búsqueda de "los rasgos fisonómicos de la bondad. Probablemente, para Ortega el utilitarismo era antes que nada una expresión del filisteísmo burgués. Su aversión por el utilitarismo más tiene el sello de la crítica cultural que el de la crítica filosófica. El utilitarismo -que en la valoración de Ortega anda cercano del darwinismo- hace de snuestra morada íntimas una "casa de contratación".

Hay una tercera intuición que probablemente sea independiente de las otras dos, pero que en gran parte las anima. "Todo un linaje de los más soberanos espiritus -escribe Ortega en Medilaciones del Quijote, Obras completas, t. I, p. 315 - viene pugnando siglo tras siglo para que purifiquemos nuestro ideal ético, haciéndolo cada vez más delicado y complejo, más cristalino y más íntimo. Gracias a ellos hemos llegado a no confundir el bien con el material cumplimiento de normas legales, una vez para siempre adoptadas, sino que, por el contrario, sólo nos parece moral un ánimo que antes de cada acción trata de renovar el contacto inmediato con el valor ético en persona. Decidiendo nuestros actos en virtud de recetas dogmáticas intermediarias, no puede descender a ellos el carácter de bondad, exquisito y volátil como el más quintaesencial aroma. Éste puede sólo verterse en ellos directamente de la intuición viva $y$ siempre como nueva de lo perfecto." Este texto puede considerarse emblemático de las ideas de Ortega sobre el lugar lógico de la empresa moral. Cabría entrever en medio de su retórica dos argumentaciones que se solapan:

A) Una filosofía moral que determine como su objetivo el hallazgo de un sistema normativo universalizable o la investigación del modo como tal hallazgo sería posible malentiende del todo la esencia de la moralidad y es contraria a las intuiciones más valiosas de la propia historia real de la moral.

B) Una tal filosofia moral es en realidad el marco conceptual que viene exigido por una moral muy concreta: una moral conformista - que dimite de la empresa autocreadora- y rigorista -que aspira a fijar un código cerrado de actuación, opresivo y estéril.

Si hay que tomar en serio lo que dice Ortega, los rasgos conceptuales de una filosofía moral poseen una íntima dependencia con respecto a los contenidos de las morales concretas que explícita o implícitamente se proponen fundamentar. Si alguien sostiene que el objeto de la moralidad es el establecimiento de un sistema de imperativos categóricos, su propósito real no será distinto del de alguien que afirme que el bien se determina por medio de un cálculo de utilidades: lo que uno y otro quieren en realidad es proporcionar a las gentes programas de acción acabados y cerrados que les eviten enfrentarse a la plenitud de la verdadera dimensión moral.

En esto, no se puede acusar a Ortega de ecléctico. Su argumentación es de un radicalismo acaso naif, pero desde luego vigoroso. Creo que Ortega fue coherente con estas afirmaciones de 1914, y quizá se halle ahí la grandeza y la miseria de su comprensión de la moral. La pars destruens de su propuesta le obligó a ser extremadamente sobrio en cualquier intento de elaboración de una ética; quizá una aversión tan extrema a la cristalización de lo moral en normas y códigos le llevó a despreciar por completo toda atención a la estructura fina de los sistemas de moralidad. Se trató de una carga excesiva. Ortega se prohíbe desde el principio preguntarse por la estructura de la racionalidad práctica y funda esa prohibición en una contumaz «genealogía de la moral». Temeroso de las sirenas del universalismo, Ortega se ató con excesiva fuerza al mástil de su nave y 
eso le impidió ver con claridad algunos escollos importantes.

La descalificación de todo universalismo y de todo cognitivismo éticos fue tan drástica e indiferenciada que terminó declarando imposible toda conceptualización en ética. Con unas bases tan inconmovibles, prácticamente cualquier forma de acercamiento a la moralidad que no consistiera en relatos en primera persona quedaba invalidada. Pero Ortega no llevó adelante su programa implícito de una "genealogía de la moral», y la explicación de esta renuncia puede tener que ver con el propio esquematismo de su punto de partida. Toda filosofia moral conceptualmente rica es un epifenómeno de la conducta moral serializada, "dogmática» y gregaria. En verdad, basta con un nivel de concep tualización muy bajo para que se pueda desenmascarar a una ética como encubridora de una imaginación moral atrofiada. Una vez que las teorías éticas traspasan ese umbral (y para que lo traspasen basta que con que se salgan del género autobiográfico), ya puede decidirse cuál es su verdadera significación: la de proveer un sustituto espurio de la genuina empresa moral. En esto último convienen filosofias morales tan opuestas como el formalismo kantiano y el utilitarismo: "no deja de ser utilitaria una moral porque ella no lo sea, si el individuo que la adopta la maneja utilitariamente para hacerse más cómoda y fácil la existencia» $(O C$, t. I, p. 315).

Si han de extraerse las consecuencias que tiene la pars destrtens de estas afirmaciones del Ortega de 1914, resulta muy difícil atribuir a sus reflexiones morales - a aquellas, por lo pronto, que desarrollan la pars construens de aquellas mismas afirmaciones - otro carácter que el de confesiones personales acerca de la idea de autorrealización y autoperfección vital que tiene de sí mismo el individuo José Ortega y Gasset.
Un nominalismo demasiado bizarro es la mejor antesala del solipsismo. Sin embargo, Ortega nos ha ofrecido en numerosos lugares ideas muy luminosas sobre las nociones de autorrealización, autocreación y autoperfeccionamiento que, además de valer para una mejor comprensión de su trayectoria biográfica, poseen gran interés tanto por lo que enuncian sobre la estructura de la personalidad moral como por lo que declaran sobre los contenidos del ideal de la vida individual.

Ahí es donde hay que buscar la concepción que Ortega tiene de la moralidad, después de contemplar cómo la ha arrancado de cuajo del territorio de la argumentación pública. La radicalidad con que Ortega da este paso no es quizá una invitación demasiado sugestiva al examen conceptual de su doctrina normativa -normativa sui generis - de la subjetividad. Hay que reconocer, sin embargo, que esa misma radicalidad puede ser interesante desde otra perspectiva distinta de la que parece importar a Ortega. Antes de entrar en la manera como traza Ortega su ideal del sujeto moral, apuntaré algo sobre esa perspectiva. Si es lícito traducir la insinuación de Ortega a un lenguaje que dista mucho del suyo, podría afirmarse que, en la base misma de la argumentación de nuestro autor, hay una tesis que cabria reconstruir de un modo parecido al siguiente. La reflexión en segundo grado sobre el fenómeno de la moralidad forma parte de contextos de acción que son ellos mismos morales. Lo moral es una dimensión de lo humano lo suficientemente amplia para que la filosofía moral no pueda aspirar a quedar emancipada de la misma. Parafraseando a alguien que constituyó un poderoso referente de Ortega, la filosofía moral que se hace depende del tipo de moral concreta a la que se quiere apuntalar conceptualmente, y esta última, 
depende a su vez, claro está, ...del tipo de hombre que se es. Caben tres niveles en una argumentación de este cstilo.

En un primer nivel, se afirma que la conceptualización de lo moral es una actividad que ejecutan seres humanos y que produce enunciados sobre la acción de seres humanos. A diferencia de los enunciados sobre amebas, seísmos y ácidos nucleicos, cuya formulación es una acción humana que no se refiere a otras acciones humanas, la filosofía moral es un ejercicio reflexivo y autorreferencial. Toda filosofía moral ha de admitir que ello es así y ha de proporcionar alguna idea sobre cómo influye este hecho en su propio ejercicio. Pero es claro que se puede dar algún paso más.

La ética es una empresa reflexiva que toma como objeto a la moral. Mas, para que esa moral de cuyo estudio se preocupa la ética no sea un mero fantasma salido de la cabeza del filósofo moral, éste no debe autoengañarse acerca de la naturaleza del fenómeno que estudia. Si ignora que la investigación teórica de la moralidad forma parte de un sistema dado de moralidad, entonces muy bien puede disculpársele que sea ingenuo respecto de las consecuencias de este hecho. Pero, una vez que ha aprendido que eso no es así, no puede prescindir de ello. Cabría que se autoengañara al respecto, pero quizá ni siquiera eso es posible, porque la consciencia de la naturaleza moral de la ética no se puede desaprender una vez aprendida. Afirmar, en efecto, ami filosofía moral no tiene nada que ver con mi vida moral» constituiria una forma entre otras de establecer reflexivamente las relaciones entre la ética de uno y la moral de uno, a. saber, proclamando que la vida moral de uno es tal que permite la edificación de una ética a la que no se le exige dependencia de las intuiciones morales concretas. (Cabría, desde luego, el extrano caso de un filósofo moral que negase lo anterior y proclamara sin ambages que la acción de elaborar su filosofía moral es inmoral con respecto a su código moral. En esta teratológica situación, el teórico moral tampoco mostraría la independencia de su ética con respecto a su moral; más bien estarfa proclamando que su moral es inconsistente -al menos en lo que toca a la evaluación de sus acciones como teórico moral- y que, por tanto, puede permitirse su curiosa esquizofrenia.) Parece, pues, muy difícil salirse de ahí.

Hay, en fin, un tercer nivel. Una vez dado por sentado todo lo anterior, el teórico puede hacer ver que ciertos cuerpos de filosofía moral están determinados de tal o cual forma por las respectivas prácticas morales que les sirven de trasfondo. Puede mostrar que, en una moral dada, cierta ética funciona de determinada forma. Podría exponer, por ejemplo, cómo en una comunidad de políticos corruptos la admisión de una versión degradada de la sética de la responsabilidad» weberiana es funcional para asegurar el equilibrio psicológico de los miembros de esa comunidad, o para permitirles hacerse pasar por virtuosos ante aquellos que les exijan virtud, y, desde luego, podría ofrecer explicaciones mucho más matizadas y ricas de fenómenos mucho más complejos. El teórico de la moral se convierte ahora en un "genealogista» de la moral y seguramente tendrá buenas razones para afirmar que su estrategia constituye la manera más lúcida y productiva de habérselas conceptualmente con la moralidad. Si, además, el genealogista recuerda los dos pasos anteriores que lo han llevado a su estrategia, hará muy bien en tomar en consideración las implicaciones pragmáticas de su genealogía de la moral. Además de una empresa de descubrimiento - de desenmascaramiento, dirá probablemente él-, la suya es una labor de reforma moral, ya 
sea que él lo quiera o no. Alguien indaga sobre las realidades encubiertas por las conceptualizaciones morales cuando le desagradan las primeras o desaprueba las segundas, y es difícil que lo haga sin el objetivo de convencer a la gente de que obra de un modo reprobable o de que sus ideas sobre cómo y por qué obra o ha de obrar así andan totalmente descaminadas.

Hay que observar, por lo que toca a los tres niveles mencionados, que nada hay que obligue a pasar con necesidad del primero al segundo y del segundo al tercero, aunque Ortega ciertamente sí lo haga y de modo sugestivo. Esto sólo bastaria para pensar que su aproximación a la moral es provocativa y fértil. Para él, es inútil hacer ética sin atender a la estructura pragmática de ese hacer, y la manera como expresa esta sugerencia es acreedora de un examen detallado. Sin embargo, parece que una atención escrupulosa a esa pragmática de la moralidad trae como consecuencia el estrechar sobremanera aquello que merece ser considerado una genuina moral. Por otro lado, hay que echar de menos en la argumentación de Ortega - si mi lectura es acertada- una matización más reposada de su actitud genealógica. Es interesante su acusación a las dos ramas principales de la filosofía moral contemporánea de constituir artificios destinados a sancionar conceptualmente una forma de vida vulgar, rutinaria, rigorista e inauténtica, pero habría sido todavía más interesante si hubiese dado una explicación más rica de la manera como ello es asi. Ortega se muestra como un crítico cultural iconoclasta e implacable, con la actitud, tan característica del reformador moral, de quien está dispuesto a arrojar por la borda intuiciones muy consolidadas siempre que se revelen caducas. ¿Es sensato seguirle por este camino? Probablemente sí, con la condición de reco- nocer en su propuesta de un ideal de autenticidad irreductible a toda determinación legal o convencional la deuda que tiene con al menos una de las dos tradiciones morales contra las que Ortega arremete. Paradójicamente, ni siquiera el lenguaje de que Ortega se sirve para sugerir una ética radical de la convicción habría sido posible sin una robusta tradición rigorista y formalista en la historia de la ética y de la moral europeas. Hay mucho en su actitud de puritano invertido a quien no basta con obrar por el puro deber, y ello no porque tal motivación de la acción le parezca una carga demasiado onerosa sino propiamente por lo contrario: él aspira a autoimponerse imperativos todavía más dificiles de cumplir y piensa que, desde la altura de esos imperativos. las normas sociales que emanan de una moralidad objetiva y los esquemas normativos que surgen del examen de la estructura de la razón subjetiva, lejos de ser maximalistas o supererogatorios, pecan de demasiado permisivos; se inventaron para hacerle fácil la vida a la gente más bien que para constreñirla y reprimirla. Es improbable que el kantiano y el utilitarista dejen de serlo por la fuerza del desenmascaramiento orteguiano, pero acaso uno y otro podrían aprender algo de él.

Por lo que hace a los otros dos niveles, resulta claro que lo correspondiente al primero de ellos se ha convertido en un lugar común de la filosofía y la teoría social contemporáneas, aunque distaba mucho de serlo en la época en que Ortega y otros conspicuos perspectivistas se hicieron cuestión del asunto. Más interés tienc el segundo nivel, y lo tiene en un sentido que no convendría desatender. Es habitual que las ideas sobre la interdependencia de ética y moral, sobre la determinación recíproca del lenguaje con que se explican las normas, el lenguaje en que se expresan las 
normas y el lenguaje con que se habla del mundo en que las normas han de cumplirse o incumplirse, que las ideas que borran o difuminan los perfiles de cada uno de estos ámbitos sean la antesala del escepticismo o del relativismo morales. Los ejercicios de desdibujamiento de límites en la teoría suelen anunciar que se avecina una moral laxa, desorientada y poco exigente. Pero no es este, descle luego, el caso de Ortega, y ha de llamar la atencion que no lo sea. Si algo hay que reprochar a la idea constructiva que Ortega se hace de la moralidad -la correspondiente a su ideal de la subjetividad, al que en seguida llegaremos-, los reproches han de apuntar más desde luego a su alto grado de exigencia que a su laxitud o a su eclecticismo. A Ortega se le daba muy poco, como hemos visto, de que su ideal del sujeto moral fuera un ideal válido para la humanidad en su conjunto. Por el contrario, no se cansaba de repetir acá y allá que lo suyo era una moral para minorías, para gentes escogidas cuya existencia es un afortunado regalo. Este aspecto de su pensamiento no es, desde luego, el más atractivo, pero la legítima antipatía que produce no debería ocultar el hecho de que, bajo la propuesta de una moral aristocrática, late la convicción de que los valores, las normas y las concepciones del bien, para que sean efectivamente tales, han de resultar de una finísima criba a partir del material moral tomado en bruto. No todo vale para Ortega, aunque tal conquista se efectúe al precio de que sean muy pocas las cosas que valen.

Si es atinada mi reconstrucción del horizonte de preocupaciones al que Ortega mira cuando se interroga por la moralidad, lo que va dicho debería ser una buena réplica a quienes pretenden convertir a nuestro autor en mero documento de la historia cultural española. Sin embargo, es corriente pensar que el meollo de la reflexión ética de Ortega no está en las mencionadas consideraciones metaéticas ni en sus intentos de mostrar lo que la moral tiene de másca. ra. El punto central de la obra de Ortega cuando se la examina en su significación para la ética es, por el contrario, su propuesta de una "moral del héroe» (Cerezo), su defensa de una ética de la vocación, de la magnanimidad y de la perfección, de una filosofía moral que, en última instancia, no es más que el resultado de entender su metafísica de una manera peculiar. "La metafísica orteguiana - ha dicho Aranguren- no es ontológica: es metafísica de 'nuestra vida' y no del ser, porque considera que es 'nuestra vida' y no el ser lo metafísicamente primarion (La ética de Ortega, Madrid, Taurus, 1958, p. 15). Pero "nuestra vida", donde "nuestra» es un giro enfático que apunta a la vida de cada uno más que a la vida de todos, es precisamente el humus de la moralidad y el único contexto en que tiene sentido preguntarse por una moral auténtica, una vez persuadidos de que la mayor parte de las cosas que se hace pasar por moralidad son, por distintos motivos, sucedáneos de la genuina moral.

En términos orteguianos, hablamos en serio de ética cuando hablamos de la perfección, de la sobreabundancia, del cumplido desarrollo del yo. El objeto de la ética no son ni las normas ni los valores ni los bienes ni los deberes, ni tampoco las acciones humanas examinadas bajo la perspectiva de alguna de las anteriores entidades. El único objeto posible de la filosofía moral -convertida ahora en algo que admitiría la denominación de «ética metafísica» tanto como la de "metafísica ética»- es el yo en su más personal concreción, soy yo mismo en mi irreductible circunstancia. A Ortega no le interesa proporcionar a los individuos un ideal normativo de su propia subjetividad, porque eso sería 
una recaida en una moral rigorista y cerrada. El ideal de la subjetividad no es algo postizo que se añada a la realidad de mi yo, sino mi propio yo cuando se le mira desde su cumplimiento pleno, desde esa norma de perfección que lleva incorporada a su esencia más íntima. Claro es que, llevada al límite esta concepción, estaríamos condenados a callar por completo en lo que toca a todos aquellos aspectos que no aparezcan en informes en primera persona, cuyo único intérprete competente sería su propio autor. Es curioso que algunas de las aporías de la filosofía moral del empirismo lógico estén en alguna medida prefiguradas por ese rigorismo moral invertido que Ortega se impuso a sí mismo. Pero Ortega si que ofreció pistas para salir del atolladero del solipsismo ético. Él estaba convencido de que el autoexamen de la realidad más íntima de cada yo habia de arrojar resultados sólidos sobre la estructura de la vida humana en general, y esto vale desde luego para comprender como imaginaba la dimensión moral propia de la aventura humana.

¿Qué intuiciones morales estaban detrás de este esquema metafísico? Aunque los supuestos básicos de su filosofía le impedían erigirlas en ideales morales, Ortega tenía sus figuras humanas predilectas, sus arquetipos del yo, sus caracteres individuales ejemplares. Ninguno de ellos puede representar, desde luego, el papel de un modelo "nomativo" a seguir; si son figuras valiosas es porque sirven para poner de manifiesto aquello que la vida humana ya es en su más destilada autenticidad, antes y con independencia de que el yo se pregunte cómo debe ser. Probablemente, el ejemplar más destacado de estos «ideales» humanos es el del deportista. El lector contemporáneo de libros de filosofía no está acostumbrado a que se le muestre como acabado ejemplo de la perfección vital, como espécimen más elocuente de la estructura metafísica de la vida humana, al alegre golfista de los años veinte que se asocia a otros conmilitones para perfilar la figura y disfrutar del campo, al jovial automovilista encandilado por el placer de la velocidad y la magia de la mecánica, al gallardo mancebo que acude a las afueras de las ciudades a jugar foot-ball y a otros entrañables personajes (por lo común de extracción desahogada) sacados de daguerrotipos de la belle époque, esa quimérica felicidad de entreguerras a la que se refirió Jaime Gil de Biedma: "Yo nací, perdonadme, / en la era de la pérgola y el tenis". Hay que hacer un esfuerzo muy sesudo para tomar todo esto en serio. Pero sin duda es un esfuerzo mas gratificante que el que cumple realizar para tomar un poco a broma otros pasajes de la obra de Ortega en donde el papel del risueño deportista pasa a ser ocupado por el rudo, esforzado y audaz guerrero, dechado también de las perfecciones que al parecer convienen a nuestro ser en el mundo.

Quizá la iconografía humana que puebla el paisaje orteguiano no sea la mejor invitación a interesarse por su filosofía moral, aunque, una vez que se pasa de los personajes arquetípicos a los personajes concretos -reales o de ficción-, el lector no tarda en reconciliarse con Ortega y con su circunstancia. Las Meditaciones del Quijote son, como se ha dicho, el primer y más robusto bastidor de la indagación ética de Ortega, y no hay duda de que aquí el talento y la sensibilidad literaria de nuestro autor son los mejores aliados de su preocupación teórica. Otro tanto puede decirse de los textos orteguianos sobre la figura de Goethe, y muy en particular del ensayo de 1932 «Pidiendo un Goethe desde dentro", en donde se hallan muchas de las claves de la visión que Ortega tiene del ideal de la personalidad. 
¿Qué quiere decir que el yo labra su propia perfección moral en una labor de autorrealización continua expresiva de la más íntima realidad de ese yo? El problema mismo - que es el central de la ética de Ortega- es un problema genuinamente goethiano, y nuestro autor es aquí consciente de su debilidad por la tradición de la Naturphilosophie, esa desheredada de la historia de la ciencia tan tentadora para muchas mentes contemporáneas. El ensayo de 1932 arranca de un lúcido examen del lugar que la figura de Goethe podría ocupar en el horizonte de valores del momento, y cllo le da pie a Ortega para un diagnóstico certero de la definitiva caducidad del ideal clasicista. Ortega se reconoce hijo de un tiempo de náufragos abandonado por toda tradición. Un año antes de la llegada de Hitler al poder, este colaborador de Die neue Rundschau ha renunciado a toda ilusión de poder reconstruir el gran relato del espíritu europeo. Goethe no puede ser ya el regio busto que preside la galeria de columnas de ese museo marmóreo que se llamó cultura occidental, porque lo que la época demanda es el difícil retrato de "un Goethe para náufragos». Y esta consciencia de orfandad, esta percepción de que el pasado, antes firme y fortalecedor, se ha mudado en un abismo, es precisamente lo que facilita a Ortega el desenmascarar a Goethe como una figura paradójicamente infiel a su propio destino. El gran titán del espíritu modemo, el alma más excelente de su tiempo, quien enseñó a deletrear la palabra Persönlichkeit con triunfal prosodia, es, sin embargo, alguien atravesado de parte a parte por la grieta de la inautenticidad. Podría decirse que la inautenticidad —en la forma de esa inautenticidad superlativa que se descubre en el emblema máximo de la tradición europea- es el fenómeno contraintuitivo y desafiante para cuya comprensión necesita Ortega levantar su doctrina del destino y de la vocación. ¿Cómo es posible el Faktum de la inautenticidad? podría ser una adecuada paráfrasis de la gran pregunta de la ética de Ortega.

La inautenticidad es para Ortega el incumplimiento de la vocación, del destino de un individuo, de su proyecto vital. El uso que hace Ortega de estos tres términos es lo bastante idiolectal como para que no esté de más recordar lo que quieren decir. La "vocación" de Ortega no coincide con el uso estándar de esta palabra en el lenguaje contemporáneo. Ese trasunto de teología protestante secularizada o a medio secularizar que cristaliza en la noción moderna de $B e$ ruf tal como la interpretó Max Weber no se compadece del todo con lo que Ortega quiere señalar como la "vocación» de alguien. Para él, vocación designa aquello que uno está intimamente "llamado" a ser en un sentido más totalizador que el expresado por la dedicación a una profesión o actividad determinada, aunque esa profesión se ejerza de un modo tan ligado a la fijación de los fines de la propia vida que pueda decirse de alguien que sse consagra» a tal o cual menester. La vocación orteguiana apunta a nuestro "yo necesario", a aquello que uno ha de lograr si no quiere fracasar como individuo. Pero el individuo, piensa Ortega, no escoge su vocación como quien elige oficio: lo único que puede hacer con ella es descubrirla y extraer las consecuencias de ese descubrimiento. Uno está «llamado» a esta o la otra realización en la vida; esa vocación pertenece a la índole de su verdadero yo, es lo que en útima instancia lo define, caracteriza e individualiza. La vocación de alguien es el destino de ese alguien. ¿Se aclara algo con esta apelación al destino? De igual modo que la vocación no equivalía al producto de una elección libre, tampoco el destino está emparentado con la ciega 
necesidad. Mi destino no es aquello que simplemente he llegado a ser porque así lo han querido los hados; no todo lo que me ocurra ni todo lo que yo haga de mí mismo tiene que ver con el «destinos. Yo puedo ser infiel a mi destino, puedo desconocer en absoluto cuál es y puedo desafiarlo a pesar de conocerlo. El destino orteguiano podria definirse acaso como "el mejor yo" de un individuo, si no fuera porque "mejor" no denota nada por el estilo de una preferencia, una valoración o el cumplimiento de un deber. Yo «debon llegar a ser el que soy, y me está vedado conocer quién es el que verdaderamente soy como no sea lográndolo, con la notable característica de que no por esforzarme mucho en la consecución de mi verdadero yo poseo garantía alguna de conquistarlo. Algo parecido le sucede a mi proyecto vital. "Proyecto" es un término que solemos asociar al ámbito de la deliberación racional de las acciones: uno proyecta hacer cosas que, por diversos motivos, considera buenas, o razonables, o convenientes, o valiosas, $y$, condicionado por la información de que dispone y por las constricciones del medio, ejecuta ese proyecto con mayor o menor eficacia. Pero el proyecto orteguiano es otra cosa. Uno no tiene proyecto vital como quien tiene programas de acción determinados y precisos; uno es su proyecto vital. Un agente estratégico elabora proyectos y luego ve si los ha llevado o no a la práctica, pero un yo orteguiano no se puede definir en su esencia de otra manera que en los términos del proyecto que lo constituye; el yo de Ortega se parece al agente estratégico tan sólo en que puede triunfar o fracasar en la ejecución de su proyecto, y de ahí que quepa hablar de proyecto. El yo orteguiano xdescubre» cuál es el proyecto vital que le corresponde descubriendo su "vocación" y su "destino".

Para muchas sensibilidades, nada de lo anterior tiene demasiado sentido. Arrastrado por ciertas connotaciones de las palabras, Ortega les atribuye un abstruso significado que no coincide ni con el que ordinariamente poseen ni con ningún otro que sea útil para elaborar una filosofía de la acción mínimamente rica. Sin embargo, creo que no conviene desatender el nervio central de lá propuesta de Ortega en el siguiente sentido. La filosofía moral de Ortega es -ya podemos afirmarlo- una teoría de la subjetividad que tiene como noción central la categoría de autorrealización, por más que haya que entender «filosofía moral», "teoría de la subjetividad» y "autorrealización» en sentidos harto problemáticos. En efecto, las condiciones que Ortega impone a una buena teoría de la subjetividad y a una correcta noción de autorrealización son sobremanera drásticas. Probablemente, con la purga conceptual a que Ortega sometió su metaética echó también a mala parte la posibilidad de toda idea inteligible de autonomía, de modo que su concepto de autorrealización acaso esté pervertido de raíz. Pero, aun con esta pesada servidumbre y todo, me parece que se puede argumentar en pro de algunos aspectos de la visión de Ortega.

El tema de la «fortuna moral» ha sido objeto de alguna atención por la ética contemporánea. Dos ensayos de Thomas Nagel y de Bernard Williams pusieron hace unos años sobre el tapete la relevancia de la idea de "fortuna" y las dificultades en que coloca a muchas nociones básicas de la teoría ética. (Ambos ensayos llevan el mismo título, "Moral Luck». El de Nagel se encontrará en sus Moral Questions, Cambridge, Cambridge University Press, 1979; el de Williams, en su recopilación igualmente titulada Moral Luck, editada en 1981 también en Cambridge. Un reciente y muy penetrante reexamen del problema es el artículo de Michele Moody-Adams, 
"On the Old Saw That Character Is Destiny", en Owen Flanagan y Amélie $O$. Rorty [eds.], Identity, Character and Morality, Cambridge [Mass.], The MIT Press, 1990.) Pero si la «fortuna moral" -el orteguiano "destino" - es una categoría central de la ética, ¿dónde situar entonces la noción de responsabilidad? ¿Puede hacérseme sistemáticamente responsable de todos y cada uno de mis actos cuando muchos de ellos han de explicarse en términos de mi "destino", de algo que escapa a mi capacidad deliberativa? ¿Y cómo determinar cuándo mis acciones son explicables en virtud de mi fortuna moral y cuándo no lo son? Nadie en la filosofía contemporánea - Ortega tampoco- ha sostenido que el destino, el carácter o la fortuna determinen completamente al sujeto moral. Los individuos pueden actuar contrariamente a su «destino" y muchas veces la perspectiva moral consiste precisamente en esa infidelidad a su propio carácter. Pero, según Ortega, cuando obramos así traicionamos nuestro «proyecto vital», somos inauténticos. ¿Podría pensarse que un poco de inautenticidad no viene mal de vez en cuan. do y que, desde el punto de vista moral, resulta más bien ineludible? Acaso haya que seguir en esto los pasos de Goethe.

Alguien podria aspirar a justificar sus acciones argumentando: "He realizado la acción $X$, que es contraria a mi código moral. Sin embargo, la acción $X$ venía determinada por mi carácter. $Y$ yo no acostumbro a desobedecer a mi carácter, porque eso me convertiría en un individuo inauténtico, y a mí la inautenticidad me repugna sobre todas las cosas. De modo que hice $X$. Este argumentador parece experimentar un conflicto moral, pero ¿lo experimenta realmente? ¿Obra con vistas a su autenticidad o simplemente determinado por los hados de su carácter, por su «fortuna moral"? ¿Es nuestro argumentador un cínico $\sin$ remedio o un hipócrita $\sin$ éxito? Este problema arrastra otros tres. En primer lugar, si alguien traiciona sistemáticamente su carácter y consolida esa práctica como un hábito, ¿podrá decirse que ello lo ha llevado a cambiar de carácter, que ya no ha de lidiar -0 ha de lidiar menos- con un «destino" que antes lo condicionaba tan fuertemente? Pero, en segundo lugar, dcómo sabe en realidad el individuo cuál es su destino o carácter? Los enunciados en primera persona sobre el destino o fortuna moral propia iposeen un estatus privilegiado que les dé preeminencia sobre otros? $\mathrm{Y}_{2}$ además, ¿qué tipo de deliberación es ésa? ¿Se ha actuado en realidad bajo la determinación del carácter ( $y$ esto equivaldria a decir que no ha habido deliberacion o que ésta se ha abandonado por debilidad de la voluntad) o bien la idea que el individuo tiene de su propio carácter ha intervenido en la deliberación junto con otros elementos y al fin se ha impuesto aunque podría no haberlo hecho (y entonces la acción no estaba determinada por el carácter)?

Estas cuestiones invitan a suscitar en torno al "destino» moral una cláusula de "agnosticismo». Es cierto que no entenderíamos la moralidad si prescindiéramos del destino, pero también lo es que las justificaciones de las acciones cn términos del destino parecen inadmisibles. A nuestro argumentador se le podría preguntar "¿cómo sabe usted con certeza cuál es su carácter? ¿Y varía su carácter si usted se esfuerza en desobedecer a lo que usted cree que es su carácter?" Probablemente no hallare mos respuesta, pero esto nos basta para desacreditar su argumentación.

Sin embargo, se puede ser agnóstico respecto del destino propio, se puede renunciar a echar mano del destino en la justificación de las acciones y seguir 
pensando que el destino $\longrightarrow$ la fortuna o el carácter- es un elemento importante de la moralidad. Además de ciego, el destino es opaco. Hay fortuna moral, pero no oráculos ni pitonisas morales. Conferir a estas nociones carta de ciudadanía ética implica renunciar a servirse de ellas como explanans de las acciones y como vehículo de justificación. Pero ni la ceguera ni la opacidad son atributos que priven de poder a quien los posee.

A Ortega le interesaba sobre todo, según se ha dicho, dar cuènta del fenómeno de la «inautenticidad». ¿Pero hay algún fenómeno relevante en filosofía práclica que corresponda a la intuición de Ortega, aparte de las argumentaciones de algunos agentes morales hipócritas? Quizá sí lo haya y merezca la pena prestarle atención. Resulta claro que la noción de autorrealización exige disponor de otras nociones que definan y limiten su alcance. La autorrealización de un individuo no coincide sin más con el mero desarrollo de ese individuo cuando no está sometido a condiciones que le impiden la libre elección de su escala de valores y fines. Un margen razonable de alibertad negativa" es condición necesaria de la autorrealización, pero, para que se pueda hablar de esta última, hay que echar mano de concreciones más finas. Puede suponerse que alguien se autorrealiza si, además, es capaz de dar cuenta reflexiva de su propio proyecto de autorrealización, es autocrítico con respecto al desarrollo del mismo y posee la suficiente coherencia para no abandonarlo, aunque pueda y deba someterlo a revisión. El yo que se autorrealiza necesita virtudes éticas por el estilo de la templanza y el coraje y virtudes dianoéticas del tipo de la capacidad de autoconocimiento, así como una disposición autocrítica que se compone a un tiempo de excelencias morales e intelectuales. Es evidente que ningün yo pucde proponerse cualquier cosa como objetivo de su autorrealización; la autorrealización no es una autodeterminación irrestricta, así como la autonomía no es una capacidad que asegure la plasticidad absoluta del yo. $\mathrm{El}$ individuo que quiere autorrealizarse necesita saber cuál es el máximo de autodeterminación que le es dado alcanzar, y es claro que ese máximo es una magnitud variable para cada individuo. No existe una medida común del dominio de los individuos sobre sí mismos, y el hallazgo de conocimiento sobre esa medida individual es una empresa inalienablemente individual. Ahora bien, ¿cómo adquieren los individuos el conocimiento que precisan sobre el grado de autodeterminación que pueden alcanzar? El aprendizaje de la medida de la autodeterminación es un proceso, sobre todo, negativo; el yo aprende aquello que no puede alcanzar cuando es lo bastante honrado y perspicaz para tomar nota de sus propios fracasos y para obrar en consecuencia. Se está en el camino del conocimiento de sí cuando se ha acumulado una considerable experiencia de los obstáculos que el propio yo opone a los programas de acción que ese mismo yo proyecta. En algún sentido, podría llamarse vinauténticos a quien se ha mostrado recalcitrantemente inepto para desarrollar estas capacidades.

El inauténtico es alguien que desconoce su verdadero yo, su «vocación», "destino" o "proyecto vital", alguien que prefiere autoengañarse o que ni siquiera es capaz de comprender que se engaña sobre su yo. Sin embargo, no hay regla alguna en la adquisición de las capacidades que evitan el autoengano; uno puede ser constante, atento, perspicaz y autocrítico $y$, sin embargo, fracasar en el conocimiento de su verdadero yo; uno puede autoengañarse durante años con la mejor voluntad, 
porque el infierno del fracaso está empedrado de buenas intenciones. Hay una clara intervención de algo parecido a la "fortuna" en el éxito de la autorrealización del individuo. Reconocer esto no nos arroja en brazos del irracionalismo; por el contrario, lo irracional es suponer que la subjetividad es absolutamente moldeable por sí misma y lo es en todo momento.

¿Recoge esta argumentación alguna de las intuiciones de Ortega en su metafísica del sujeto moral? A mi juicio, sí recoge lo más interesante de su noción del "destino", aunque sin duda deje escapar muchas connotaciones de la misma que acaso sean fecundas. En ese sentido, la ética de Ortega es fresca, desafiante y fértil. Convenientemente des- pojada del bloqueo interpretativo a que la han condenado ciertas limitaciones del contexto en que se produjo, contiene tesis muy valiosas para la discusión filosófica contemporánea, y sería una absurda injusticia desaprovecharlas a causa de cegueras o estrabismos históricos. La principal objeción que cabría formular a la fecundidad del enfoque orteguiano tiene que ver con su voluntaria reducción a una teoria de la subjetividad moral. Probablemente, la noción de autorrealización por sí sola es insuficiente para vertebrar una sólida filosofía moral, y necesitaria apoyarse en otras categorias cuya operatividad viene impedida por la purgación conceptual a que Ortega sometió a su enfoque de la moralidad. Habent sua fata philosophi. 